\section{Visual pattern discrimination in cats after removal of the superior colliculi*}

\author{
KENNETH V. ANDERSON and MARCUS R. WILLIAMSON \\ Department of Anatomy, Emory University, Atlanta, Ga. 30322
}

Two groups of cats were trained to make a visual discrimination between two patterns in a standard discrimination apparatus. Animals in Group I were trained until they reached a criterion level of $90 \%$ correct responding, had bilateral lesions made in the superior colliculi (SC), and were retrained. Animals in Group II had bilateral lesions made in the SC and were then trained on the visual discrimination task. While all animals in Group I relearned the discrimination to criterion in 60 trials or less, animals in Group II either failed to learn the problem or required more than 380 trials to reach criterion.

For many years, the superior colliculi (SC) have been considered to be important structures in the visual system. Experimental support for such a notion has come from a variety of sources, including anatomical, physiological, and behavioral experiments. The findings in behavioral studies on experimental animals subjected to bilateral ablation of the SC have depended on the nature of the study. Those investigations that have emphasized the general neurologic status of such animals (Denny-Brown, 1962; Sprague, 1966) as opposed to formal discrimination testing have described a wide variety of postoperative symptoms including: visual neglect, reduced visual fields, alteration in tactile sensitivity, and inattention to and poor localization of auditory stimuli. While these findings seem to indicate that there is a general decline in discriminative capacity subsequent to collicular removal, investigations which have utilized rigorous testing of specific visual discriminations have generally failed to find losses. Studies testing brightness or pattern discriminations in rats (Ghiselli, 1937), cats (Fischman \& Meikle, 1965), and monkeys (Rosvold, Mishkin, \& Szwarcbart, 1958) have shown that neither discrimination is seriously disrupted following colliculectomy.

Only recently, in experiments with hamsters and monkeys, has performance on specific discrimination tasks been shown to be seriously disrupted following removal of the SC. In one experiment (Schneider, 1969), hamsters were unable to make a pattern discrimination following colliculectomy. In another experiment (Anderson \& Symmes, 1969),

*This investigation was supported by a McCandless grant from Emory University and by Research Scientist Award No. MH 16077 to KVA from the National Institute of Mental Health. Publication No. 1008, Department of Anatomy, Division of Basic Health Sciences. Emory University. monkeys performed poorly on or were unable to learn a movement discrimination after the colliculi were removed. In both of these experiments, the most profound visual deficits were observed when comparisons were made between the learning rates of intact animals and learning rates obtained in animals that acquired the task for the first time after the SC were removed. The goal of the present experiment was to explicitly examine the extent to which experimental design factors might influence postoperative performance on visual discrimination tasks. In one experimental design, animals were trained to make a pattern discrimination, had their $\mathrm{SC}$ removed, and were retrained on the discrimination. The extent to which the $\mathrm{SC}$ influence discrimination performance was assessed by comparing postoperative behavior with preoperative behavior. In a second experimental design, animals had their
$\mathrm{SC}$ removed and were then trained on a pattern discrimination. The effect of SC lesions on performance in these animais was assessed by comparing their behavior on the task with that of intact animals trained on the same task.

\section{SUBJECTS}

Six adult cats were used as Ss. Three cats were trained on a pattern discrimination task, had their SC removed, and were retrained on the discrimination (Group I). The remaining three animals (Group II) underwent surgery for removal of the colliculi prior to being trained on the pattern discrimination problem. The pattern problem consisted of a discrimination between targets that contained alternating black and white stripes ( $3 / 8 \mathrm{in}$. wide) oriented horizontally (rewarded target) or vertically (unrewarded target).

APPARATUS AND PROCEDURE

Visual discrimination training was conducted in a modified version of the Thompson-Bryant (1955) apparatus. Alterations involved elimination of the grid floor and a threefold increase in the dimensions. Two transverse partitions, 15 in. from either end, divided the interior of the box into start, choice, and goal compartments. The stimuli (5.75 in. square) were attached to doors (hinged at the top) in the partition between choice and goal compartments. The lower edges of the doors and their attached stimulus patterns were flush with the floor. There was a 12-in.-long divider between the doors. Each stimulus was illuminated by a $125 \cdot \mathrm{W}$ spotlight fixed to the side of the apparatus at a point about 36 in. from the discriminanda.

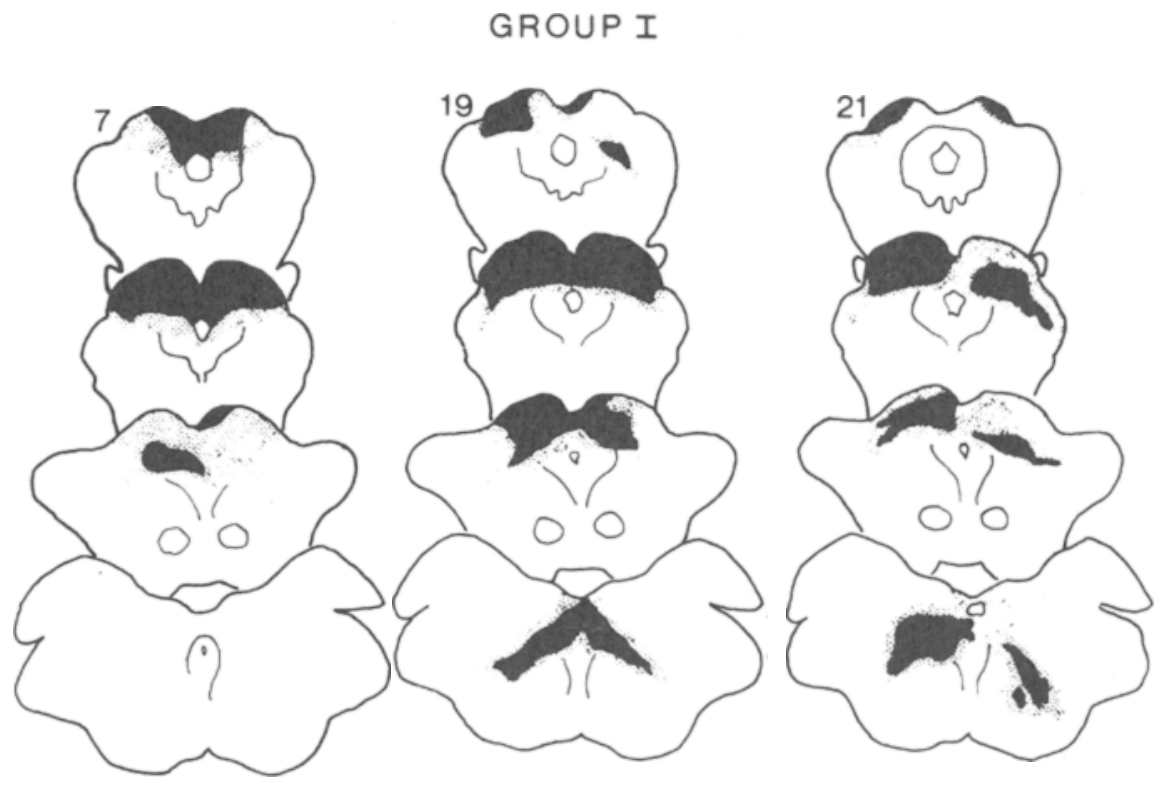

Fig. 1. Reconstructions of tectal lesions in the three cats of Group I. 


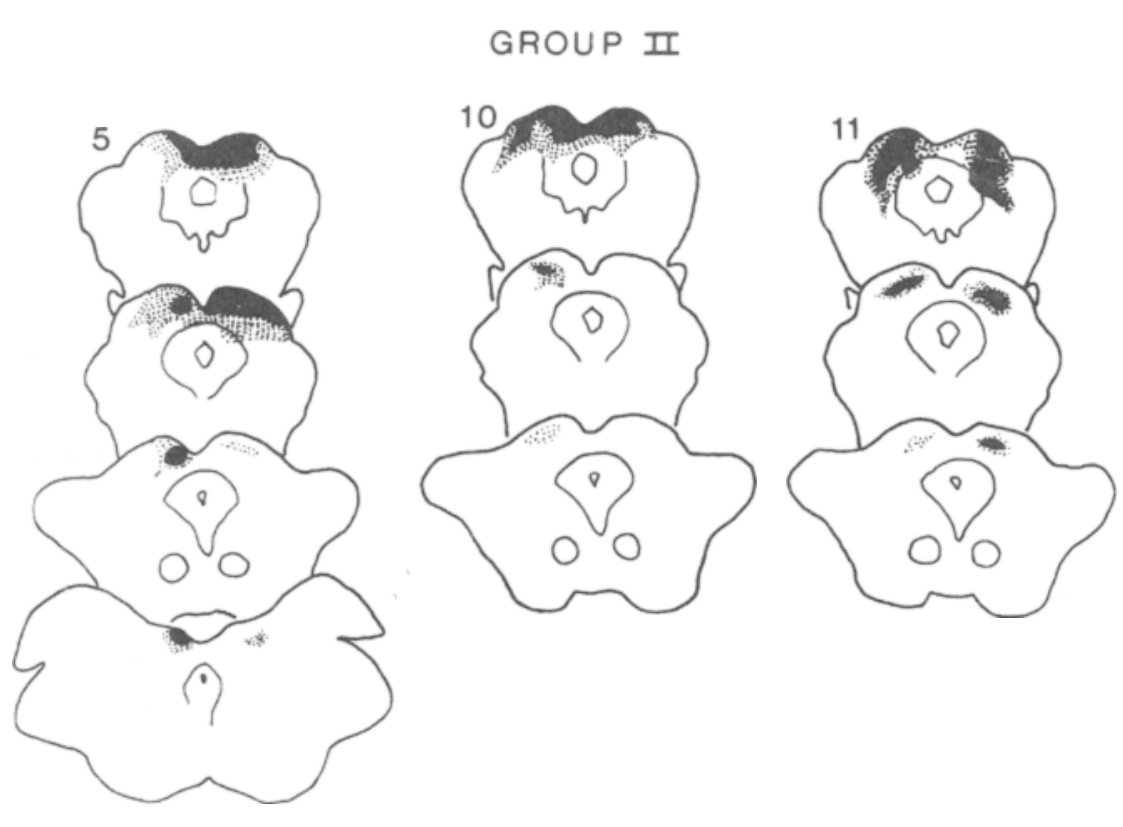

Fig. 2. Reconstructions of tectal lesions in the three cats of Group II.

Animals were trained to run from the startbox to one of the doors at the other end of the apparatus. The door displaying the incorrect stimulus (vertical stripes) was locked; the correct door (horizontal stripes) could be pushed open to permit access to a food reward.

An error was defined as contact with the incorrect door. Ss received 20 trials a day for 5 to 6 days a week. A correction procedure was used, and the stimulus panels were changed from side to side on successive trials, according to a Gellerman series (1933). Training was discontinued when animals reached a criterion of $90 \%$ correct responses on 3 successive days or when they had run 600 trials. Postoperative training was initiated 14 days after surgery.

Superior colliculus operations were carried out under deep Nembutal anesthesia ( $35 \mathrm{mg} / \mathrm{kg}$ ) and aseptic conditions. An opening was made in the calvarium with a trephine and widened with rongeurs to expose the posterior marginal, posterior suprasylvian, and middle and posterior ectosylvian gyri of both hemispheres. The dura was resected, the hemispheres retracted, and aspiration of the colliculi accomplished under direct visualization, using a glass tube drawn out at one end. At the conclusion of postoperative training,

Table 1

Trials to Criterion and Evaluation of Lesions

\begin{tabular}{|c|c|c|c|c|c|c|c|c|}
\hline \multicolumn{3}{|c|}{ Behavior } & \multicolumn{6}{|c|}{ Histology } \\
\hline & \multirow{2}{*}{$\begin{array}{c}\text { Pre-Op } \\
\text { Learn- } \\
\text { ing }\end{array}$} & \multirow{2}{*}{$\begin{array}{c}\text { Post-Op } \\
\text { Relearning }\end{array}$} & \multicolumn{3}{|c|}{ Superior Colliculus } & \multirow[b]{2}{*}{$\begin{array}{c}\text { Teg- } \\
\text { mentum }\end{array}$} & \multirow[b]{2}{*}{$\begin{array}{c}\text { Pre- } \\
\text { tectum }\end{array}$} & \multirow[b]{2}{*}{$\begin{array}{l}\text { Posterior } \\
\text { Thalamus }\end{array}$} \\
\hline Animal & & & $\begin{array}{c}\text { Anterior } \\
1 / 3\end{array}$ & $\begin{array}{c}\text { Medial } \\
1 / 3\end{array}$ & $\begin{array}{c}\text { Posterior } \\
1 / 3 \\
\end{array}$ & & & \\
\hline \multicolumn{9}{|c|}{ Group I } \\
\hline 7 & 140 & 20 & + & ++ & ++ & + & 0 & + \\
\hline 19 & 60 & 40 & ++ & ++ & + & + & o & + \\
\hline 21 & 60 & 60 & ++ & ++ & + & + & + & + \\
\hline \multicolumn{3}{|c|}{ Initial Learning } & \multicolumn{3}{|c|}{ Group II } & & & \\
\hline 5 & \multirow{2}{*}{\multicolumn{2}{|c|}{$\begin{array}{l}380 \\
560\end{array}$}} & + & ++ & ++ & $\mathbf{0}$ & + & 0 \\
\hline 10 & & & + & + & t+ & + & 0 & 0 \\
\hline 11 & \multicolumn{2}{|c|}{$600^{*}$} & + & + & ++ & + & 0 & 0 \\
\hline
\end{tabular}

+ Indicates slight to moderate damage; ++ indicates complete destruction; 0 indicates no damage.

* Animal failed to reach criterion; number indicates point at which training was discontinued.

the cats were perfused with saline and $10 \%$ formalin, and their brains blocked and soaked in a $20 \%$ formal-sucrose solution for 2 or 3 days. Frozen brain sections ( 25 microns thick) were taken at 250-micron intervals through the lesion, stained with cresyl violet, and used to reconstruct lesions in all animals.

\section{RESULTS}

For all animals, performance on the pattern discrimination task and extent of tectal damage are summarized in Table 1. Three animals (Nos. 7, 19, and 21) suffered nearly complete destruction of the colliculi and had only modest damage inflicted to the pretectum, tegmentum, and posterior thalamus. The remaining three animals (Nos. 5, 10, and 11) had extensive damage throughout the posterior and middle portions of the SC but little or no damage in the anterior portions. These latter animals also had either no damage or only slight damage in the pretectum, tegmentum, and posterior thalamus.

Informal neurological assessment of postoperative behavior began as soon as animals recovered from the anesthesia. A spectrum of postoperative symptoms was observed including: fixed gaze, dilated and unresponsive pupils, narrowed visual fields, and impaired visual placing and visual following. The free field activity of the cats (e.g., locomotor behavior, avoidance of objects, etc.) appeared to be normal in all but one respect: there was a marked inability to negotiate successfully vertical distances of more than 12 in. The fixed gaze and visual-following disorders did not substantially improve during the 6-week postoperative period. All other disorders disappeared within 10 days following surgery.

Individual performances of the six cats used in this experiment on the pattern discrimination are shown in Table 1. It can be seen that all animals in Group I relearned the discrimination problem at the same (S 21) or a faster (Ss 7 and 19) rate after removal of the colliculi than they did preoperatively. Table 1 also shows that animals in Group II (Ss that had their colliculi removed and were then trained on the pattern discrimination) either failed to learn the discrimination (S 11) or had extreme difficulty in mastering the problem (Ss 5 and 10 ).

The results of the present experiment indicated that performance on a visual pattern discrimination after removal of the SC depended upo the amount of training experienced by an animal prior to lesioning. Animals that were trained to a criterion of $90 \%$ correct responding 
before colliculectomy showed little or no effect of the ablation during postoperative testing. In contrast, animals trained on the discrimination for the first time following $\mathrm{SC}$ ablations were seriously impaired. A similar finding, also in cats, has been reported following lesions in the somatosensory system (Anderson \& Mahan, 1970). The present findings may explain why few studies have reported discrimination deficits following lesions of the SC, since most investigations of the role of the colliculi have utilized experimental designs in which each animal served as his own control. It would appear that a within-Ss experimental design, by itself, may not be sufficient for assessing the contribution of specific brain nuclei to higher sensory function when ablation techniques are used.

In some studies of collicular function (Myers, 1964; Fischman \& Meikle, 1965), animals with damage restricted to the $\mathrm{SC}$ failed to show postoperative deficits on visual discrimination tasks, while animals in which damage extended beyond the
$S C$ into the pretectum and tegmentum, were impaired. Five animals in the present study suffered some tegmental damage, and some animals had a small amount of pretectal $(\mathrm{N}=2)$ or posterior thalamic $(\mathrm{N}=4)$ damage. However, in the present experiment, the largest lesions were not associated with the greatest postoperative deficits. On the contrary, the animals that had the smallest lesions, i.e., those animals in Group II, showed the most severe postoperative impairments. These latter three animals suffered only minimal damage to the rostral colliculi, tegmentum, and pretectum.

\section{REFERENCES}

ANDERSON, K. V., M MHAN, P. E. The role of the thalamus in pain perception. Anatomical Record, 1970, 166, 272.

ANDERSON, K. V., \& SYMMES, D. The superior colliculus and higher visual functions in the monkey. Brain Research. $1969,13,37-52$.

DENNY-BROWN, D. The midbrain and motor integration. Proceedings of the Royal Society (Medicine), 1962, 55 . 527-538.

FISCHM AN, M W., \& MEIKLE, T. H Visual intensity discrimination in cats after serial tectal and cortical lesions. Journal of Comparative \& Physiological Psychology, 1965, 59,193-201.

GELLERMAN, L. $W$. Chance orders of alternating stimuli in visual discrimination experiments. Journal of Genetic Psychology, 193, 42, 206-208.

GHISELLI, E. E. The superior colliculus in vision. Journal of Comparative Neurology, 1937,67, 451-467.

MYERS, R. E. Visual deficits after lesions of brain stem tegmentum in cats. Archives of Neurology, 1964, 11, 73-90. ROSVOLD. H. E., MISHKIN, M., \& SZWARCBART, M. K. Effects of subcortical lesions in monkeys on visual-discrimination and single-alteration performance. Journal of Comparative \& Physiological Psychology, 1958, 51. 437-444.

SCHNEIDER, G. E. Two visual systems. Science, 1969, 163, 895-902.

SPRAGUE, J. V. Visual, acoustic, and somesthetic deficits in the cat after cortical and midbrain lesions. In D. P. Purpura and M. D. Yahr (Eds.), The thalamus. New York: Columbia University Press, 1966. Pp. 391-417.

THOMPSON, R., \& BRYANT, H. J. Memory as affected by activity of the relevant receptor. Psychological Reports, $1955,1,393-400$ 